single volume. London's Leonardo contains four highly competent and complementary essays, which go a long way towards providing a definitive account of Hooke, while leaving open the road (or preparing the way) for a full intellectual biography.

Hooke was wealthy at his death, much of his money having come from his work helping to resurvey London after the Great Fire of 1666. In his essay, Michael Cooper describes this work pleasantly and informatively. That Hooke should have embarked on it when he was already fully occupied with his scientific work for the Royal Society is remarkable and bespeaks his devotion to London and its inhabitants. There were many problems. With street widening, residents had to be compensated fairly for the land they were to lose. Buildings had different owners on different floors, and some structures had 'interleaved' with their neighbours. An accurate survey was needed, and it relied on instruments, some devised by Hooke, that were an integral part of the 'scientific revolution'. Hooke's contributions to the survey were substantial.

Jim Bennett's fine paper, which is profusely illustrated, deals with Hooke's instruments and inventions more generally, revealing their extraordinary range and ingenuity: time-pieces, air pumps, telescopes and microscopes, meteorological and oceanographic instruments, the universal joint and many other items. Hooke believed in the use of instruments to enhance the senses, as can be seen from his controversy with the Polish astronomer Johannes Hevelius, who still advocated naked-eye instruments for astronomy. Hooke was clearly on the winning side. Everyone knew that optical instruments had imperfections, and Hooke applied himself to the endless task of their improvement.

Michael Hunter writes about Hooke's philosophy of nature and his ideas on scientific method. Regarding the latter, Hooke was not a baconian inductivist (nor, indeed, was Bacon), but rather a hypothetico-deductivist. Although Hooke made some use of baconian tables of 'presence', 'absence' and 'degrees', he gave a clear example of the formulation and

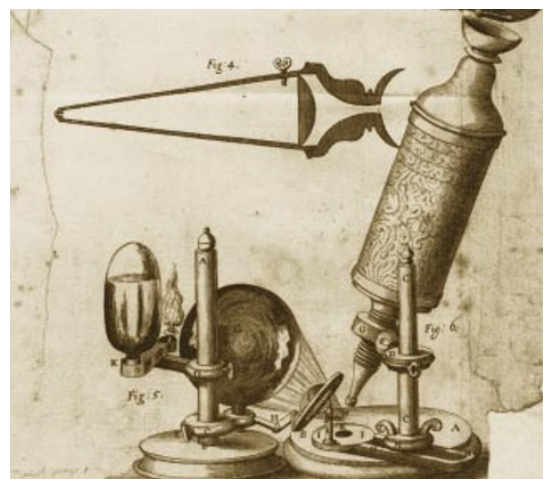

Instrumental to his success: Hooke relied on optical devices such as this compound microscope.

\title{
Art
}

\section{Science in site}

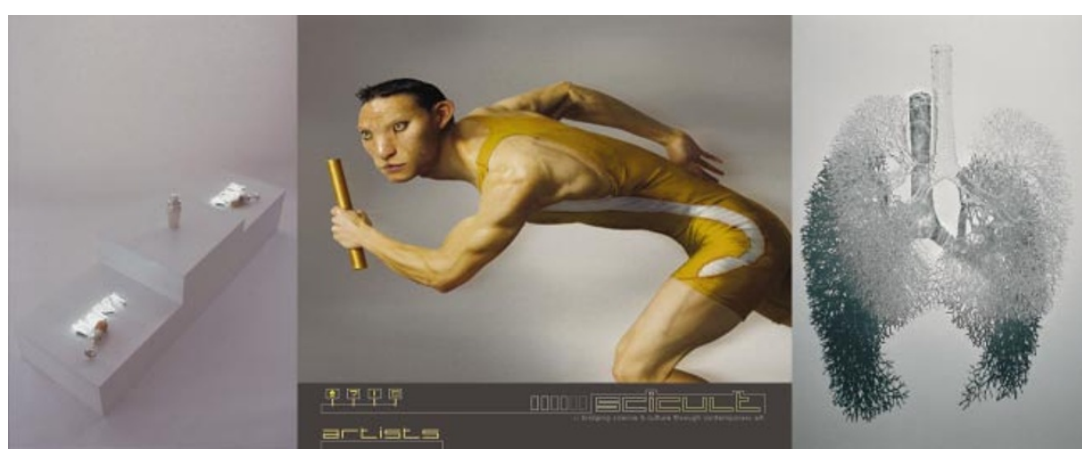

Taking issue: Happy Hour by Fernando Arias (left) examines AIDS treatments; Daniel Lee focused on evolution for Cheetaman (middle); and Annie Cattrell's Capacity was inspired by the breath of life.

The website scicult.com is a science-related contemporary art gallery - and an act of love. The small group of 'sci-art' specialists who launched it earlier this year are idealists, committed to promoting a quality marriage of art and science.

The group has already signed up 20 significant artists, including Annie Cattrell and Fernando Arias, some of whose whose work is shown here. The art is exhibited in the online gallery, and some pieces will eventually be available for sale.

But scicult.com is more than a gallery. It publishes an expanding range of intelligent features about contemporary sci-art, and has

testing of hypotheses in science. He proposed the idea of pole-wandering to account for cyclical interchanges of the levels of land and sea (to explain the presence of inland fossils). Such movements in the position of the geographic poles, if they occurred, would, over time, produce changes in the direction of the meridian at any given locality. Hooke then suggested astronomical methods for the accurate determination of the meridian, which should be measured over a period of years to look for changes. A first attempt at determination failed because of poor weather and the idea was not pursued, being pushed aside by Hooke's manifold other activities, but the hypothetico-deductive method was clearly enunciated.

This example, in a way, renders superfluous historians' worries about what Hooke meant by what he mysteriously called 'philosophical algebra', presumably some kind of 'routinizable' procedure for conducting science. Of course, knowing about the 'form' of scientific method tells us little about how Hooke's creative process worked. Hunter, unlike another Hooke aficionado, Steve Shapin, eschews discussion of the significance of Hooke's social status for his scientific practice. Rather, Hunter gives an excellent exposition of Hooke's Micrographia, which links back to the discussion of instruments, and further illustrates his procedures. longer-term plans to develop an 'introduction service' for scientists and artists who seek collaborating partnerships. It is also in the process of acquiring a permanent, real-world gallery in which it can exhibit more experimental works.

The website is attractive and functional. Artworks are well displayed against a dark-grey background and can be enlarged with a click of the mouse. The features are timely and wellwritten, but suffer the plague of many web pages designed primarily for visual impact: the text, reversed out white on dark grey, is a strain to read on the screen.

Alison Abbott

www.scicult.com

Lisa Jardine's paper is less precisely focused than the other three. She explicates details of Hooke's relations with Robert Boyle, and writes about Hooke's work on pressures, the magnitude of subterranean gravitational attraction and geology. But she is chiefly interested in his health and his self-medication (recorded in his diary), which eventually more or less killed him. Hooke left no will, and his family fell on his fortune after he died. They were not interested in preserving his name, so for many years he was a rather forgotten figure (Jardine suggests). But his time has come: the comprehensive bibliography of London's Leonardo shows just how many works have been written about him since'Espinasse's biography.

This prompts a thought. People's interests can often be judged by their libraries. Hooke's printed library sale catalogue survived, and some years ago I attempted an approximate classification of his books. The number of literary items (languages, grammar, philology, poetry, plays, epigrams and biographical works) easily exceeded the number in any of the categories of mathematics, astronomy, logic, physics, architecture, machines and so on. Is there perhaps another Hooke to be explored: the man of letters?

David R. Oldroyd is in the School of History and

Philosophy, University of New South Wales,

Sydney 2052, Australia. 